\title{
Weathering's beneficial effect on waste-stabilised rammed earth: a chemical and microstructural investigation
}

\author{
Alessandro Arrigoni ${ }^{\mathrm{a}, *}$, Renato Pelosato ${ }^{\mathrm{a}}$, Giovanni Dotelli ${ }^{\mathrm{a}}$, Christopher T.S. Beckett ${ }^{\mathrm{b}}$, Daniela Ciancio ${ }^{\mathrm{b}}$ \\ a Dipartimento di Chimica, Materiali e Ingegneria Chimica “G. Natta”, Politecnico di Milano, Piazza Leonardo da Vinci 32, Milano, 20133, Italy \\ ${ }^{\mathrm{b}}$ School of Civil E' Resource Engineering, The University of Western Australia, 35 Stirling Highway, Perth, WA 6009, Australia
}

\section{H I G H L I G H T S}

- Microstructure of RE stabilised with waste materials has been investigated.

-Weathering improved the mechanical strength of SRE mixes.

- Fly ash promoted autogenous healing during wet-dry cycles.

- Waste materials proved to be an effective solution to stabilise nonexpansive soils.

\section{G R A P H I C A L A B S T R A C T}

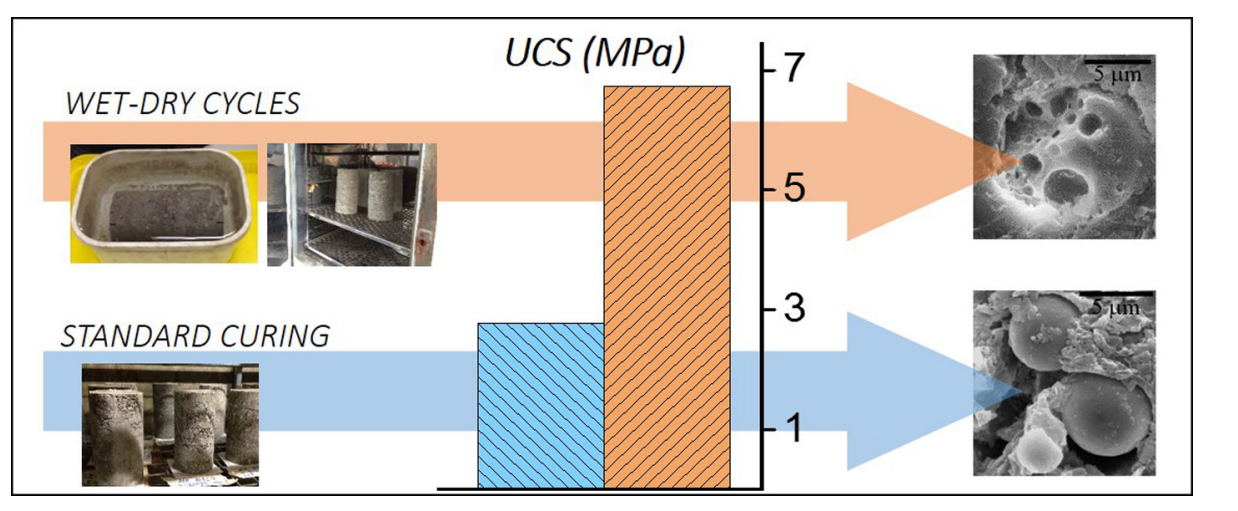

\begin{abstract}
A B S T R A C T
The most common method to improve the mechanical properties of a rammed earth mix is to add chemical stabilisers like cement and/or lime. Varying the stabiliser type will affect strength gain but also the environmental impact. In this paper, the effect of wetting-drying cycles on the long-term unconfined compressive strength of stabilised rammed earth (SRE) mixes was investigated through the chemical characterisation of the soil components and microstructural analyses. The mixes were stabilised using different agents characterised by distinct environmental impacts, such as cement, calcium carbide residue and fly ash. These last two are considered waste materials, significantly affecting their use's associated environmental implications. The results of this experimental campaign support others in this series of work and showed an improvement of the mechanical properties after cyclic wetting-drying due to the formation of new hydration products which bound particles together. The use of waste materials proved to be an effective solution to stabilise RE.
\end{abstract}

(ㄷ) 2017 Elsevier Ltd. All rights reserved.

Strength

Microstructure

Autogenous healing

\footnotetext{
* Corresponding author at: Dipartimento di Chimica, Materiali e Ingegneria Chimica "G. Natta", Politecnico di Milano, piazza Leonardo da Vinci 32, 20133 Milano, Italy

E-mail address: alessandro.arrigoni@polimi.it (A. Arrigoni).
} 


\section{Introduction}

Rammed earth (RE) is an ancient building technique that consists of compacting slightly wet soil in layers within formwork. The high density due to compaction and the suction of the partially saturated micro-pores give RE materials a compressive strength of $0.5-2.5 \mathrm{MPa}$ [1]. In order to meet modern construction standards and requirements, stabilisers are added to RE mixtures in many countries around the world [2-4]. The most used stabilisers are cement and lime but the need to reduce the environmental impacts in the building sector demands the use of more sustainable stabilisers (e.g. waste materials, biopolymers and geopolymers [5-13]).

One of the waste materials traditionally used for soil stabilisation is Fly Ash (FA), the fine particle residue transported by flue gas as a result of power generation from coal-fired power stations. FA chemical composition depends on the coal ignited and typically comprises aluminosilicates with some iron and/or calcium oxides and minor concentrations of $\mathrm{Na}, \mathrm{Mg}, \mathrm{P}, \mathrm{S}, \mathrm{K}, \mathrm{Ti}, \mathrm{Sr}$ and $\mathrm{Ba}$. Typically, FA has quartz and mullite as major crystalline phases and $40-80 \%$ by weight (wt \%) of amorphous phases. FA represents $85-95 \mathrm{wt} \%$ of the total ash generated from coal combustion, which accounts for 5-20 $w t \%$ of feed coal [14]. Coal is and will remain until 2030 the second-largest energy source worldwide, with an average increase rate of $0.6 \% /$ year [15]. An estimate of annual worldwide generation of FA is approximately 780 million tonnes [16]. Even though efforts have

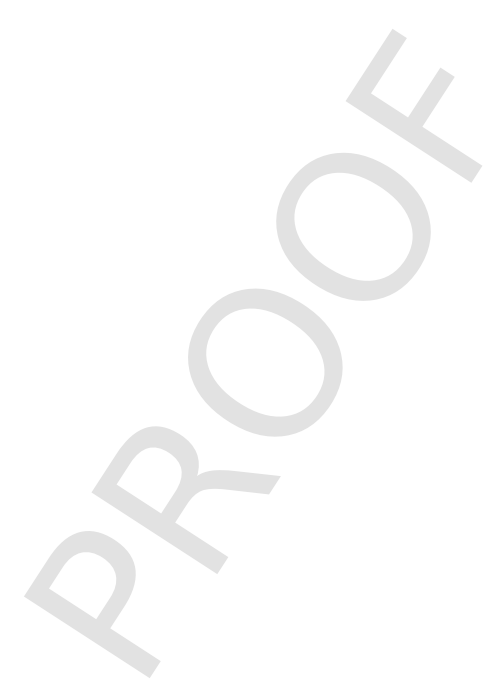

been undertaken to recycle some FA, the remainder is waste and has to be discharged into ash ponds, lagoons or landfills.

The main uses for recycling FA are concrete production, road base construction, soil amendment, zeolite synthesis and use as a filler in polymers. The effect of FA on the compressive strength of soil is due not only to its free lime content alone but also to hydraulic and pozzolanic reactions [17]. FA rich in free lime is self-cementing while FA containing a low amount of lime needs an activator such as Portland cement or added lime to produce cementitious compounds [18].

Soil stabilisation is a well-established discipline within geotechnical engineering. Cement is preferred for lowly cohesive (sandy) soils but it loses effectiveness for highly plastic soils. For sandy soils, RE literature recommends a cement content in the range of $5-12 \%$ of soil mass, considering that the compressive strength of the mixture nominally increases linearly with the increase in cement content [19]. Cement is the most commonly used stabiliser and its popularity is due to quick strength gain and the ability to obtain desirable mechanical properties with relatively low amounts of stabiliser. Portland cement mixed with water gives rise to hydrated compounds, such as calcium silicate hydrate $(\mathrm{CSH})$ and calcium aluminate hydrate $(\mathrm{CAH})$, which cover the soil particles and later crystallise to link them [18].

Lime stabilisation is the preferred methods for plastic clays. The addition of lime results in an immediate cation exchange, in which calcium ions normally replace cations on the clay surface. The high alkaline $\mathrm{pH}$ resulting from lime treatment leads to long term pozzolanic reactions: silica and alumina dissolved from the clay mineral structure react with $\mathrm{Ca}^{2+}$ in the pore water to form $\mathrm{CSH}$ and $\mathrm{CAH}$ in a similar process to cement hydration [20]. The formation of cementing agents is considered the main source of strength improvements in 
lime stabilised soils and it is strongly dependant on the structure of the soil, the temperature and the soil water content [21,22]. Finally, carbonation is a reaction between lime and carbon dioxide present in the air to form calcium carbonate. For soil stabilisation carbonation should be avoided as calcium carbonate is a less effective stabiliser than hydration products [23,24].

Two different types of lime are available to stabilise soils: $h y$ draulic and hydrated lime. Differences derive from the chemical composition of the original limestone and while the hydraulic lime sets through hydration (with a similar behaviour to cement), hydrated lime sets through carbonation and needs a pozzolanic material to form cementitious products. A by-product that has very similar chemical and mineralogical composition of hydrated lime is carbide lime, also known under the name "Calcium Carbide Residue" (CCR) [25]. CCR is a by-product of acetylene production through the hydrolysis of calcium carbide

$$
\mathrm{CaC}_{2}{ }^{(s)}+\mathrm{H}_{2} \mathrm{O}^{(l)} \rightarrow \mathrm{C}_{2} \mathrm{H}_{2}{ }^{(g)}+\mathrm{Ca}(\mathrm{OH})_{2}{ }^{(a q)}+64 k c a l
$$

CCR has been already used for agricultural purposes, water treatment, soil stabilisation, mortars and compressed blocks. The first attempts to use CCR as a stabiliser for masonry units were presented by Horpibulsuk et al. [26] and by Consoli et al. [27], while the feasibility and the environmental advantages of using CCR combined with FA for RE construction were presented in [28]. Using CCR as substitute for commercial hydrated lime would reduce the concerns related to its waste disposal and all the environmental impacts related to limestone exploitation and calcination.

Most of the studies on RE stabilisation focus on the mechanical properties of the material on a short-term basis (e.g. 28-day strengths), while long term performance is often ignored. However, weathering cycles over the material's lifespan may effect mechanical performance. In this study, we investigated the strengths of stabilised rammed earth (SRE) materials, stabilised with either cement or waste materials (i.e. CCR and FA) before and after wetting-drying regimes. Particular emphasis was given to the long-term behaviour of the alternative stabilisation by relating the mechanical properties and durability to material microstructural features.

\section{Materials and methods}

\subsection{Materials}

\subsubsection{Engineered soil}

Although several studies on earthen construction indicate that the Particle Size distribution (PSD) cannot be used as a discriminating parameter for the selection of a suitable soil for construction [29,30], a heterogeneous PSD, including both fine and coarse particles, is generally recommended when building with earth $[31,32]$. Moreover, laboratory tests tend to underline that the activity of the clayey proportion in the soil is at least as impacting as its PSD [33]. The base in situ soil used here was a typical soil from Perth, Western Australia, which largely comprised sand. To improve its poor grading, both coarse (gravel) and fine particles (silty clay) from local quarries were added. The percentage of the single components were determined following the recommendations made by Houben and Guillaud [32]. The use of an "engineered" soil over a natural soil permitted tighter control over material mineralogy and grading [23]. The resulting mixture, which will be referred to as Engineered Local Soil (ELS), was composed of $60 \%$ local soil, $30 \%$ clayey soil from a nearby quarry and $10 \%$ single sized gravel $(10 \mathrm{~mm})$. The PSD of the added silty clay, measured according to AS 1289.3.6.1 [34] and AS 1289.3.6.3 [35], demonstrated a composition of $66 \%$ clay and $28 \%$ silt. Chemical analysis showed a composition of $65 \%$ kaolin, $28 \%$ quartz and 5\% muscovite. X-ray diffraction analysis on an oriented and glycolated sample of the silty clay revealed no presence of expansive clays and confirmed the typical low-activity of the kaolinite. The specific gravity of the silty clay soil, calculated according to AS 1289.3.5.1 [36], was $2.75 \mathrm{~g} / \mathrm{cm}^{3}$. The PSD of the ELS is shown in Fig. 1.

\subsubsection{Stabilisers}

The cement (CEM) used is a General Purpose Cement Type GP according to AS 3972 [37] composed of Portland cement and limestone (less than 7\%). FA came from a coal power plant in Western Australia (WA) and had a median particle diameter of $15 \mu \mathrm{m}$. Chemical compositions of CEM and FA are reported in Table 1 and PSDs are shown in Fig. 1. The FA composition showed a low calcium content and was therefore classified as class F ash based on ASTM Standard Specification C 618 [38]. CCR was provided by an acetylene producer located in WA and comprised calcium hydroxide (ca. $95 \mathrm{wt} \%$ ) and a small amount (ca. $5 \mathrm{wt} \%$ ) of calcium carbonate. PSD of CCR was slightly shifted towards larger diameters compared to the other stabilisers (Fig. $1)$.

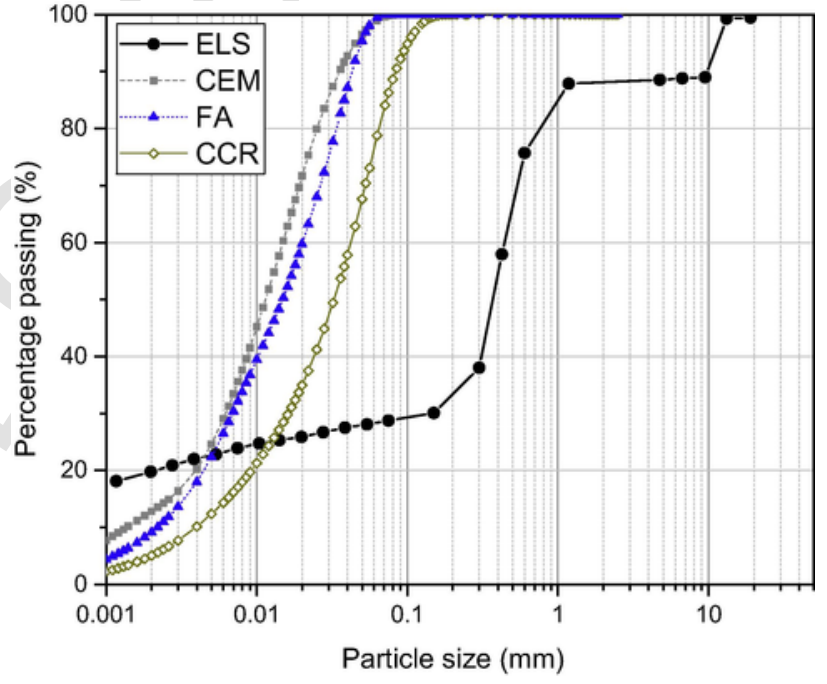

Fig. 1. Particle Size Distribution of the engineered local soil (ELS), cement (CEM), fly ash (FA) and calcium carbide residue (CCR).

Table 1

Cement (CEM) and fly ash (FA) chemical analysis via X-ray fluorescence (wt $\%$ ).

\begin{tabular}{lll}
\hline & CEM & FA \\
\hline $\mathrm{Na}$ eq. & - & 0.7 \\
$\mathrm{Al}_{2} \mathrm{O}_{3}$ & 5.4 & 27.4 \\
$\mathrm{CaO}$ & 63.7 & 0.9 \\
$\mathrm{Fe}_{2} \mathrm{O}_{3}$ & 2.8 & 8.1 \\
$\mathrm{~K}_{2} \mathrm{O}$ & - & 0.6 \\
$\mathrm{MgO}$ & 1.3 & 0.8 \\
$\mathrm{Na}_{2} \mathrm{O}$ & 0.5 & 0.3 \\
$\mathrm{P}_{2} \mathrm{O}_{5}$ & - & 0.4 \\
$\mathrm{SiO}_{2}$ & 20.4 & 58.7 \\
$\mathrm{SO}_{3}$ & 2.7 & 0.2 \\
$\mathrm{SrO}^{\mathrm{TiO}}$ & - & 0.1 \\
$\mathrm{Tr}_{2}$ & - & 1.6 \\
\hline
\end{tabular}




\subsubsection{Mixes}

The prepared mixes are presented in Table 2. FA was used together with an activator: cement in one case and CCR in the other. Quantities of FA for each mix were determined according to previous works in order to optimise their pozzolanic potential $[6,27]$, considering that a quantity higher than $25 \%$ led to compaction difficulties [6]. Traditional RE (ELS) was prepared as reference.

\subsection{Methods}

\subsubsection{Specimen manufacture}

All the specimens were compacted at their Optimum Water Content (OWC). Determination of the OWC was carried out using the Modified Proctor Test (MPT) [39], which uses a compactive effort $\left(2703 \mathrm{kN} / \mathrm{m}^{2}\right)$ more similar to the one used on site than the Standard Proctor Test $\left(596 \mathrm{kN} / \mathrm{m}^{2}\right)$ [40]. The MPT for the unstabilised mix (ELS) was performed according to AS 1289.3.2.1-2009 [41]: the soil was oven-dried (for $24 \mathrm{~h}$ at $105^{\circ} \mathrm{C}$ ), mixed with water and left for 7 days in sealed containers in order to guarantee a uniform water content before the test. After compaction, the dry density was verified by placing a sample in the oven for $24 \mathrm{~h}$ at $105^{\circ} \mathrm{C}$. The procedure was repeated with a different amount of water and the OWC was assumed to be the one giving the Maximum Dry Density (MDD). For the stabilised mixes, the standard procedure was slightly modified. After wetting, the mixture was not left in sealed containers due to stabiliser activation. Compaction was instead completed within $45 \mathrm{~min}$ after wetting to prevent interference with the test. Moreover, the water content of the material could not be confirmed by oven-drying it after compaction because of the aforementioned chemical reactions that produce a loss of evaporable water [42]. The water content at test was therefore estimated from the amount of water added during the test and the MDD was calculated accordingly.

Before compaction the mixtures were manually mixed until a uniform distribution of the components was achieved. CCR exits the acetylene production plant in the form of lime putty. Before testing, the water content of the putty was measured and the excess water was accounted for in the OWC calculations.

At least 3 specimens for each mix and curing condition (described in the following section) were prepared. Specimens were manufactured in five layers of equal mass and volume using a volume-controlled rammer head. The resulting cylinders were of $100 \mathrm{~mm}$ diameter and $200 \mathrm{~mm}$ height.

\subsubsection{Ageing conditions}

\subsubsection{Standard (S)}

After preparation, specimens were moved to a curing room at constant high humidity (RH: $96 \pm 2 \%)$ and temperature $\left(21 \pm 1{ }^{\circ} \mathrm{C}\right)$. Specimens were cured for 28 days and transferred to an unconfined

Table 2

Mix overview. $\mathrm{Wt} \%$ for the stabilisers is referred to the weight of the engineered local soil (ELS) alone while \% for the optimum water content (OWC) is referred to the total solids in the mixture, including the stabilisers. FA: Fly Ash; CEM: Cement; CCR: Calcium Carbide Residue; MDD: Maximum Dry Density; DD: Dry Density at test.

\begin{tabular}{lllllll}
\hline MIX & $\begin{array}{l}\text { FA } \\
{[\mathrm{wt} \%]}\end{array}$ & $\begin{array}{l}\text { CEM } \\
{[\mathrm{wt} \%]}\end{array}$ & $\begin{array}{l}\text { CCR } \\
{[\mathrm{wt} \%]}\end{array}$ & $\begin{array}{l}\text { OWC } \\
{[\%]}\end{array}$ & $\begin{array}{l}\text { MDD [kg/ } \\
\left.\mathrm{m}^{3}\right]\end{array}$ & $\begin{array}{l}\text { DD [kg/ } \\
\left.\mathrm{m}^{3}\right]\end{array}$ \\
\hline ELS & - & - & - & 8.0 & 2160 & 2080 \\
CEM-FA & 5.0 & 5.0 & - & 8.2 & 2100 & 1980 \\
$\begin{array}{l}\text { ELS } \\
\text { CCR-FA }\end{array}$ & 25.0 & - & 6.2 & 10.7 & 2010 & 1900 \\
ELS & & & & & & \\
\hline
\end{tabular}

compressive strength (UCS) testing machine. Contrary to cement hydration, lime-soil reactions extend beyond the 28th day of curing. To highlight the possible benefits of longer curing times, CCR-containing specimens were also tested after 56 days curing. However, tests at 56 days revealed no further increase in strength.

\subsubsection{Wet and dry cycles (WD)}

One of the main concerns about earthen construction is durability $[43,44]$. Adding chemical stabilisers to the mixture improves service life and reduces maintenance. Different tests have been proposed worldwide to estimate the durability of earthen construction materials. Here, we followed the wire brush test proposed by the ASTM international standards organization (ASTM D559 [45]). The test was originally developed for soil-cement mixtures used in road construction but different authors considered it suitable to test the durability of cement stabilised earth, since the test has similar conditions to heavy driving rain on wall surfaces $[46,47]$. After preparation, specimens were moved to the curing room for 7 days. At the end of storage, specimens were cyclically submerged in water at room temperature for $5 \mathrm{~h}$ and placed in an oven at $71{ }^{\circ} \mathrm{C}$ for $42 \mathrm{~h}$. Before each cycle, two of the specimens were brushed on all areas with a wire brush. In addition to procedures recommended in ASTM D559, after 12 cycles specimens were dried to constant mass at $110^{\circ} \mathrm{C}$ and placed again in the curing room for 7 days before UCS testing. The additional week in the curing room was intended to provide the specimens with suctions and moisture contents at testing similar to the specimens cured under standard conditions. Given the slower speed of lime-soil reactions, we adapted the standard for soil-cement mixtures to soil-lime mixtures by curing specimens containing CCR for 28 days before beginning the wet and dry cycles; the implicit assumption was that after 16 weeks the lime would be fully reacted.

\subsubsection{Characterisation methods}

\subsubsection{Unconfined compressive strength (UCS)}

UCS was performed at constant displacement rate of $0.3 \mathrm{~mm} / \mathrm{min}$ until failure. Soft-board sheet (chipboard) of $19 \mathrm{~mm}$ thickness was used as contact material between the specimen and the machine platens. Adapting its shape to the irregular surface of the specimen, the chipboard permits a uniform distribution of the axial stress. When the surface of the specimen was particularly rough after the wire brush test, the surface was levelled with a mitre saw. The UCS results of the levelled specimens were corrected using the slenderness ratio correction factor proposed by Ciancio et al. in [48]. The dry density of the specimens at the moment of testing was calculated by measuring their weight and volume before testing and by transferring part of the crushed sample to an oven at $105^{\circ} \mathrm{C}$ and drying for $24 \mathrm{~h}$ to measure the water content.

\subsubsection{Thermogravimetric-differential thermal analysis (TG-DTA)}

Microstructural characterisation tests, described below, were performed on samples obtained from specimens at the end of the standard and wet-dry testing phases. Thermo-gravimetric analyses were carried out in a nitrogen atmosphere with a Seiko 6300 simultaneous TG-DTA instrument, with heating ramps of $10^{\circ} \mathrm{C} / \mathrm{min}$. In a typical experiment, about $50 \mathrm{mg}$ of sample were heated from room temperature to $900{ }^{\circ} \mathrm{C}$. Three weight losses were quantified: the stepwise loss occurring at $115-150^{\circ} \mathrm{C}$, that was attributed to $\mathrm{CSH}$ or $\mathrm{CAH}$ gels following Sharma et al. [49], the weight loss due to dehydroxylation of $\mathrm{CAH}$ at around $260{ }^{\circ} \mathrm{C}$ and the stepwise loss occurring nearby $750{ }^{\circ} \mathrm{C}$ that is usually related to the decomposition of carbonates (mainly Calcite, $\mathrm{CaCO}_{3}$ ). 


\subsubsection{Fourier transform infrared spectroscopy (FTIR)}

The Fourier transform infrared (FTIR) spectra were recorded with a Jasco mod. 615 spectrometer at $8 \mathrm{~cm}^{-1}$ resolution. A few milligrams of powder were mixed with potassium bromide $(\mathrm{KBr})$ in a mortar and pelletised in order to perform the measurement.

\subsubsection{X-ray powder diffraction (XRPD)}

The X-ray powder diffraction (XRPD) data were recorded on small fractions of each specimen that were crushed before analysis. The diffraction patterns were recorded with a Bruker D8 diffractometer (Bruker AXS) using graphite-monochromated $\mathrm{Cu}-\mathrm{K} \alpha$ radiation. The patterns were recorded in the 2-theta range $2-70^{\circ}$. The step scan was $0.02^{\circ} 2 \theta$ and the measurement time of $1 \mathrm{~s}$ per step. The phase analysis was made using the Diffrac Plus Evaluation software (Bruker AXS) and PDF-2 Database.

\subsubsection{Scanning electron microscopy (SEM)}

The morphology of the samples was observed with a Cambridge Stereoscan 360 Scanning Electron Microscope. Both polished sections and fractured surfaces were analysed. To obtain the polished sections, samples were incorporated in an organic resin before polishing. All the samples were gold coated to prevent charging effects.

\subsubsection{Mercury intrusion porosimetry (MIP)}

The pore structure of the different specimens was investigated by means of mercury intrusion porosimetry (Micromeritics AutoPore IV $9500)$ at pressures up to $414 \mathrm{MPa}$. The pore diameter interval investigated was from $6 \times 10^{5}$ to $60 \AA$.

\section{Results}

\subsection{Optimum moisture content and maximum dry density}

Mix OWCs and MDDs are reported in Table 2 and represented in Fig. 2. The influence of chemical additives on the OWC and MDD was dependent on the type of soil and on the stabiliser. Previous investigations found that the addition of Portland cement neither affected the OWC nor the MDD when compaction tests were per-

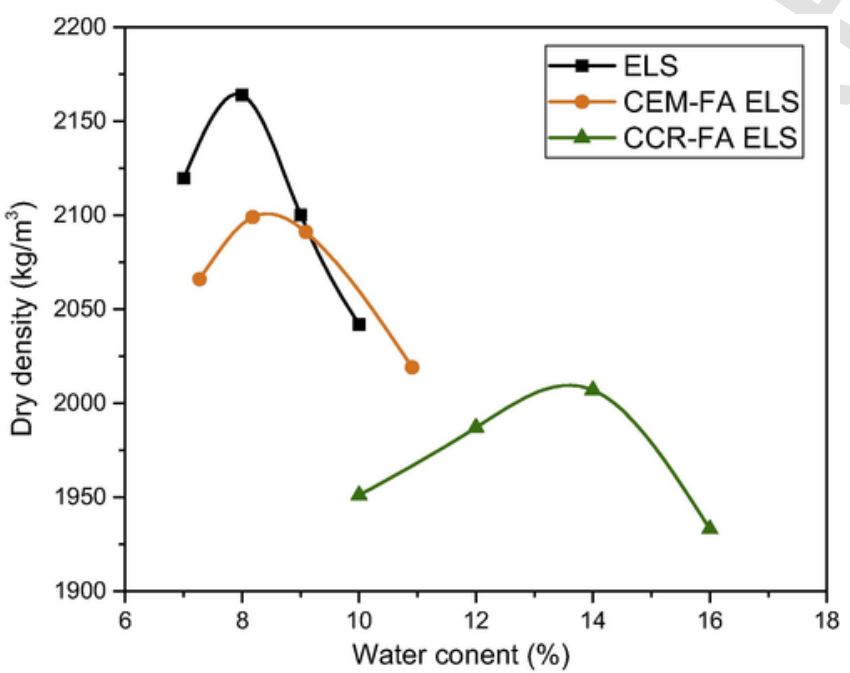

Fig. 2. Dry density versus water content of ELS, CEM-FA ELS and CCR-FA ELS compacted according to the Modified Proctor Test. ELS: Engineered Local Soil; CEM: Cement; FA: Fly Ash; CCR: Calcium Carbide Residue. formed immediately after mixing with water [19,50]. Others found that MDD increased when clays were stabilised with cement and FA [51] and that OWC increased and MDD decreased in expansive soils stabilised with lime and FA (e.g. [52,53]). The spherical shape of FA may favour densification during compaction but the particles have a lower specific gravity than the soil. In our case, both the stabilised mixes had higher OWCs and lower MDDs than the unstabilised soil. Among the stabilised mixes, CCR-FA ELS showed the lowest MDD and highest OWC, likely due to the higher amount of FA in the mixture. Actual dry densities (DD) of the specimens used for testing (Table 2) were lower than the MDD, highlighting the limitations of manual manufacturing.

\subsection{Mechanical characterisation}

After 28 days in a controlled chamber, a small fraction of chemical additive combined with FA substantially improved compressive strength over the unstabilised mixture: $>4$ times in the case of CEM-FA stabilised specimens and $>2$ times in the case of CCR-FA. UCS results, summarised in Fig. 3, confirm that the cementitious gel that binds particles together became the major source of strength for SRE [54].

Specimens that went through the cyclic wetting-drying further improved their compressive strength by circa (ca.) 35\% for CEM-FA stabilised specimens and ca. $160 \%$ for the CCR-FA. Previous research has shown that compressive strength can vary considerably with changes in water content, even for stabilised materials, which is now attributed to changes in internal suction $[23,55,56]$. The average water contents at testing are reported in the text boxes in Fig. 3; specimens after wet-dry cycles exhibited a much lower water content at testing. Notwithstanding the different degree of saturation at the time specimens were placed in the curing room, changes in water content for samples equilibrated to the same conditions suggest a variation of the internal microstructure. Microstructural characterisations of the specimens were thus performed to understand if a change in the microstructure could explain the change in water content and net increase in mechanical resistance.

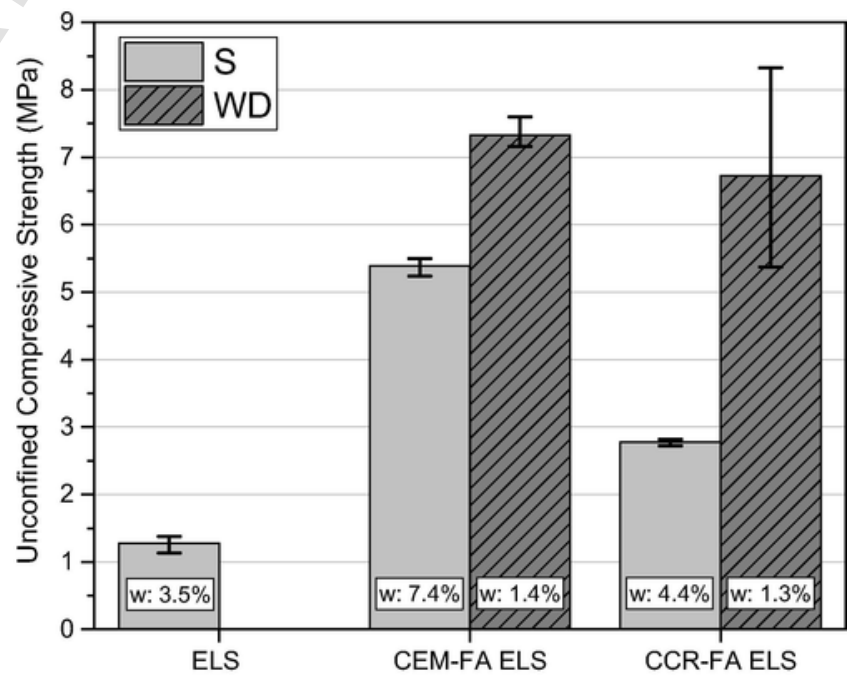

Fig. 3. Unconfined Compressive Strength results of samples cured in standard conditions (S) and after wet and dry cycles (WD). The error bars indicate the minimum and maximum for each group of specimens. In the text boxes, w (wt\%) indicates the water content at test (on dry basis). ELS: Engineered Local Soil; CEM: Cement; FA: Fly Ash; CCR: Calcium Carbide Residue. 


\subsection{Microstructural characterisation}

After UCS testing, specimens were stored at room temperature sealed in plastic bags and analysed for microstructural characterisation at the same age (ca. 8 months).

\subsubsection{Thermogravimetric analysis}

The TGA and DTG results are shown in Fig. 4. In heating the unstabilised soil (black line), two main weight losses were detected: the dehydroxylation of kaolin between 400 and $600{ }^{\circ} \mathrm{C}$ and a small loss at $600-800^{\circ} \mathrm{C}$ due to carbonates. In the CEM-FA ELS (Fig. 4a) and CCR-FA ELS (Fig. 4b) samples two additional losses were detected, occurring at about $115-150^{\circ} \mathrm{C}$, and about $260{ }^{\circ} \mathrm{C}$, respectively. The first one was attributed to the dehydration of CSH [49], while the second one to dehydration of $\mathrm{CAH}$, according to Ref. [57]. The weight loss occurring between 115 and $150{ }^{\circ} \mathrm{C}$ was $0.03 \%$ for the unstabilised sample, $0.17 \%$ for CEM-FA ELS $(S), 0.19 \%$ for CEM-FA ELS $(W D), 0.08 \%$ for CCR-FA ELS $(S)$ and $0.26 \%$ for CCR-FA ELS $(W D)$. The loss at ca. $260{ }^{\circ} \mathrm{C}$ appeared in both CEM-FA ELS $(S)$ and $(W D)$ samples, but was larger for $(W D)$; this was an indication that cement had already hydrated to a certain degree under the standard curing conditions but a slightly higher amount of hydrated phase de- veloped thanks to wetting and drying cycles. Indeed, this effect was intensified in the CCR-FA ELS samples. In the sample cured under standard conditions, no CAH peak was observed, while it did appear in the sample that underwent the wetting and drying cycles. The opposite occurred for the weight loss due to carbonates. These slightly decreased in the CEM-FA ELS (WD) sample with respect to CEM-FA ELS $(S)$, while the same effect was stronger if comparing CCR-FA ELS $(W D)$ with CCR-FA ELS $(S)$. These results suggested that, in the samples cured in standard conditions, calcium hydroxide (which is a hydration product in cement-containing samples and was added as CCR in the others) was prone to carbonation, while in the (WD) samples it reacted with FA to form new hydration products (CSH and $\mathrm{CAH})$. Interpreted carbonation amounts are further confirmed by the FTIR measurements reported in the following section.

\subsubsection{Infrared absorption spectroscopy}

The carbonate decomposition step between 600 and $800{ }^{\circ} \mathrm{C}$ in Fig. 4 could be partially attributed to the weight loss associated with the collapse of the layered structure of the clay. To independently confirm the presence of different amount of carbonates in the samples, FTIR measurements were carried out (Fig. 5). The absorption bands at 1430 and $880 \mathrm{~cm}^{-1}$ were due to the presence of calcium carbonate (calcite) in the sample [58]. As predicted by the TG plots, the spectra
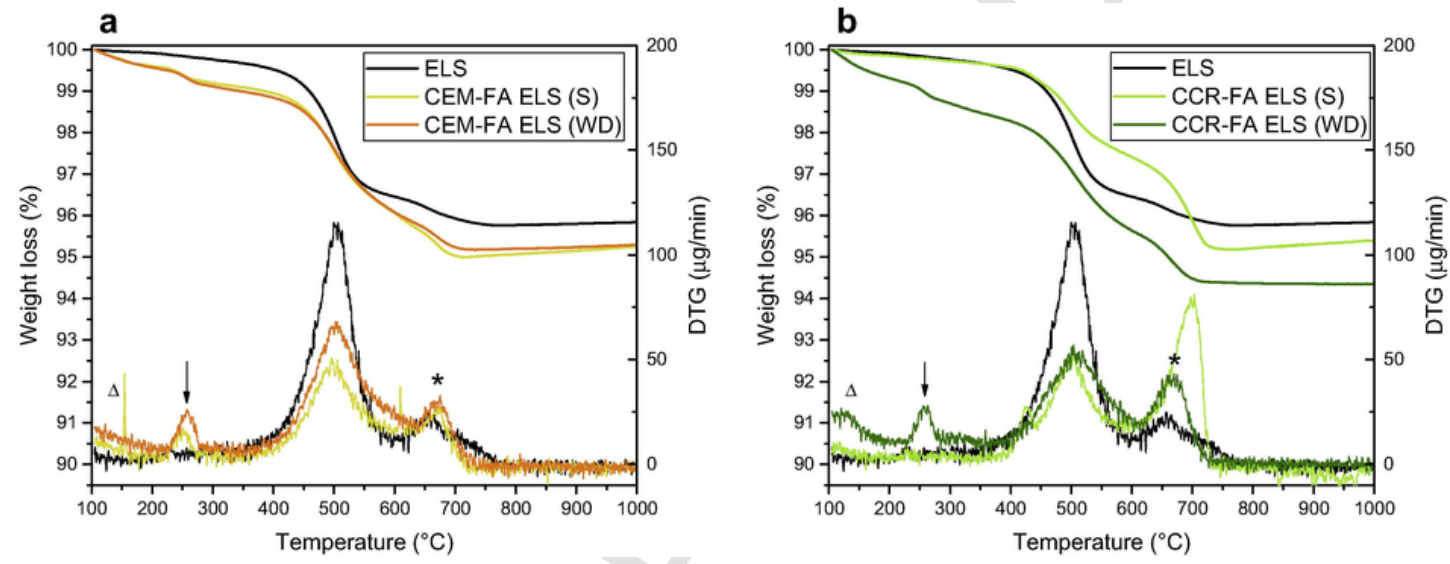

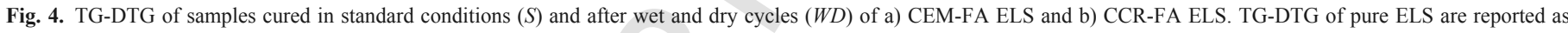

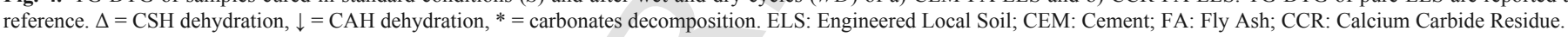
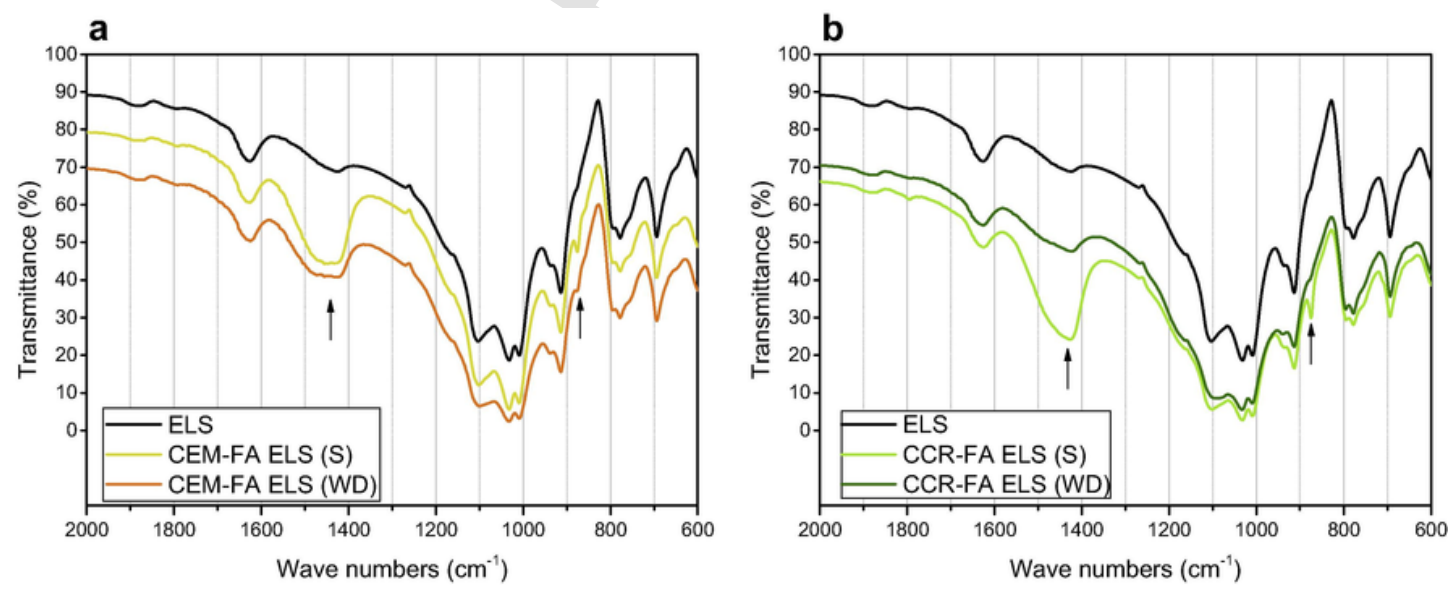

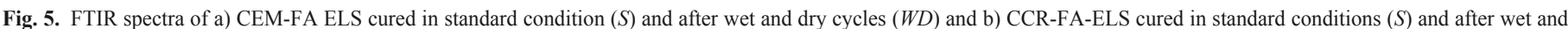

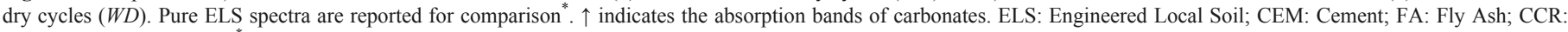
Calcium Carbide Residue. ${ }^{*}$ Shifted upwards by $15 \%$ in Y axis. 
in Fig. 5 show important changes in the samples cured under different conditions. Specifically, the absorption bands of carbonates are much more noticeable in the CCR-FA ELS $(S)$ sample with respect to the corresponding (WD) sample (Fig. 5b). Contrariwise, in agreement with the TG experiments, the change in the amount of carbonates was only minor between CEM-FA-ELS $(S)$ and $(W D)$ samples (Fig. 5a). It is worth recalling that in the CEM-FA ELS, calcite originated from the carbonation of the calcium hydroxide produced by the cement hydration reaction, while in the CCR-FA ELS samples it originated from the carbonation of the calcium hydroxide comprising the main chemical component of the CCR. These results seem to suggest that the calcium hydroxide in the $(S)$ samples carbonated while in the $(W D)$ samples it was consumed by the pozzolanic reaction with the FA.

\subsubsection{Porosimetry}

Mercury intrusion revealed a total porosity of the samples in line with the dry density: the higher the density, the lower the total porosity (Table 3 ). The porosimetry of the different samples is shown in Fig. 6 where $a-b)$ represent the cumulative percentage of pore volume on the total volume while, c-d) represent the incremental intrusion volume versus diameter and e-f) represent the differential specific intrusion volume versus diameter $(\delta \mathrm{V} / \delta \mathrm{D})$. ELS showed pores distributed mainly between 2000 and $100 \AA$ with an average pore diameter of $764 \AA$ (Fig. 6a). CEM-FA ELS cured under standard conditions showed a similar distribution, slightly shifted to smaller diameters (Fig. 6a, c and e). Conversely, CCR-FA ELS cured in standard conditions showed a more uniform distribution with higher concentrations of large (>1000 $\AA$ ) and small pores (60-100 $\AA$ ) compared to ELS (Fig. 6b, d and f). After cyclic wetting-drying, CEM-FA ELS pore volumes for pores between 200 and $300 \AA$ slightly reduced, to be replaced by bigger (400-2000 $\AA$ ) and smaller pores (60-100 $\AA$ ). Higher small pore volumes were probably due to the formation of hydrated products that filled larger pores $[59,60]$. Increased large pore volumes could be explained by the cracking of the matrix due to either the formation of new products or microscopic shrink-swell phenomena during the cycles. CCR-FA-ELS displayed a 'tri-modal' distribution after wetting-drying, with maxima at roughly $40,000 \AA, 4000 \AA$ and $100 \AA$ and a decreased volume of pores ca. $2000 \AA$. The high volume of small pores is most likely due to the increased formation of hydrated products (with respect to the $(S)$ sample) inundating previously larger pores. The drop in pores ca. $2000 \AA$ could be attributed to autogenous healing; slower pozzolanic reactions in CCR-FA ELS could have sealed any cracks that formed during the cycles $[18,61]$.

\subsubsection{X-ray powder diffraction}

The X-ray diffraction patterns of CEM-FA ELS and CCR-FA ELS samples cured in standard conditions $(S)$ are reported in Fig. 7a) and b) respectively, and are compared with the same samples that

Table 3

Mercury Intrusion Porosity results. ELS: Engineered Local Soil; CEM: Cement; FA: Fly Ash; CCR: Calcium Carbide Residue.

\begin{tabular}{llll}
\hline MIX & $\begin{array}{l}\text { Porosity } \\
{[\%]}\end{array}$ & $\begin{array}{l}\text { Average Pore Diameter } \\
{[\AA]}\end{array}$ & $\begin{array}{l}\text { Total Pore Area } \\
{\left[\mathrm{m}^{2} / \mathrm{g}\right]}\end{array}$ \\
\hline ELS & 19.2 & 764 & 5.91 \\
CEM-FA ELS $(S)$ & 21.9 & 649 & 6.73 \\
CEM-FA ELS & 21.5 & 636 & 7.61 \\
$(W D)$ & & & \\
CCR-FA ELS $(S)$ & 24.1 & 1041 & 5.31 \\
CCR-FA ELS & 24.7 & 437 & 13.1 \\
$(W D)$ & & & \\
\hline
\end{tabular}

went through wet-dry cycles $(W D)$. The diffraction patterns of the starting substrates and stabilisers are also reported as a reference. Local soil mainly comprised quartz $\left(\mathrm{SiO}_{2}\right.$, ICDD PDF \#00-046-1045), with small traces of calcite $\left(\mathrm{CaCO}_{3}\right.$, ICDD PDF \#00-005-0586). In the clayey soil fraction quartz, kaolinite (ICDD PDF \#01-079-1570) and traces of muscovite (ICDD PDF \#01-082-2450) were detected. In cement, clinker components like calcium disilcate (larnite, $\mathrm{Ca}_{2} \mathrm{SiO}_{5}$, ICDD PDF \#00-033-0302) and calcium trisilicate $\left(\mathrm{Ca}_{3} \mathrm{SiO}_{4}, \mathrm{ICDD}\right.$ PDF \#00-031-0301) and a small amount of calcite were present, while CCR constituted portlandite $\left(\mathrm{Ca}(\mathrm{OH})_{2}\right.$, ICDD PDF \#00-004-0733) and calcite. Finally, the pattern of FA showed the presence of crystalline quartz and mullite. The phase analysis of the cured mixes revealed diffraction peaks of quartz, kaolinite, and calcite in all samples, indicating that the crystalline phase content in the $(S)$ and $(W D)$ samples did not change significantly. No peaks of the common hydration products of pozzolanic reactions $\left(\mathrm{CSH}, \mathrm{C}_{2} \mathrm{ASH}_{8}, \mathrm{C}_{4} \mathrm{AH}, \mathrm{C}_{3} \mathrm{AH}_{6}\right.$, $\mathrm{C}_{3} \mathrm{AS}_{2} \mathrm{H}_{2}$ [62]) were detected. Besides, these hydrated phases often develop in amorphous or very poorly crystalline phases, and cannot be detected with XRD experiments [62]. Small peaks were detected in the CEM-FA ELS $(S)$ and $(W D)$ samples and in the CCR-FA ELS (WD) sample at about 27.5 and $27.9^{\circ} 2 \theta$ that could not be identified unambiguously. The presence of these peaks seemed to mimic the appearance of the CSH decomposition step detected in the TG-DTA plots of the corresponding samples at about $260{ }^{\circ} \mathrm{C}$ (see Fig. 4 above), suggesting that they could belong to some kind of hydrated phase. A tentative identification could suggest they belonged to a hydrated aluminium oxide phase (ICDD PDF \#00-022-1119) and a mixed calcium-iron hydrate phase (ICDD PDF \#00-003-1121) which may have originated from the reaction of FA particles (rich in $\mathrm{Al}$ and $\mathrm{Fe}$, see Table 1) with water and $\mathrm{Ca}(\mathrm{OH})_{2}$. Alternatively, these peaks could arise from a modification of the clay structure. No traces of residual portlandite (main peak at about $18^{\circ} 2 \theta$ ) were found in any of the samples, suggesting that the lime originally present in the mixtures was completely consumed in the pozzolanic reactions.

\subsubsection{Scanning electron microscopy}

Fig. 8 reports the SEM pictures of CEM-FA ELS samples cured under $(S)$, panel a, and $(W D)$ conditions, panel b. The two images are representative of the interfaces between aggregate particles (sand, mostly $\mathrm{SiO}_{2}$ ) and the binder. In the sample cured in standard conditions (a) the matrix around the aggregate particle appeared porous and 'loose', while there seemed to be a well-formed bond with the aggregate particle. A small FA particle can be seen (labelled "2" in Fig. 8a) that showed no evidence of reaction with the surroundings. On the contrary, the matrix of (WD) samples (Fig. 8b) appeared more compact and densified. Voids were filled and the FA particles were reacted and perfectly embedded in the binder matrix.

Fig. 9 reports the backscattered electron SEM images of CCR-FA ELS samples cured in standard conditions $(S$, panel a) and in $(W D)$ conditions (panel b). The amount of FA particles was much larger in these samples and they were fully dispersed in the matrix. In the sample cured under standard conditions, only some of the particles were strongly bound to the surrounding phases, suggesting a poor degree of reaction, while in the $(W D)$ sample they were embedded in the matrix suggesting that the pozzolanic reactions had gone to completion. In the insets, high magnification images of typical FA particles are reported.

\section{Discussion}

The specimens that underwent the wet and dry cycles exhibited a higher compressive strength compared to the same mixtures cured 
a
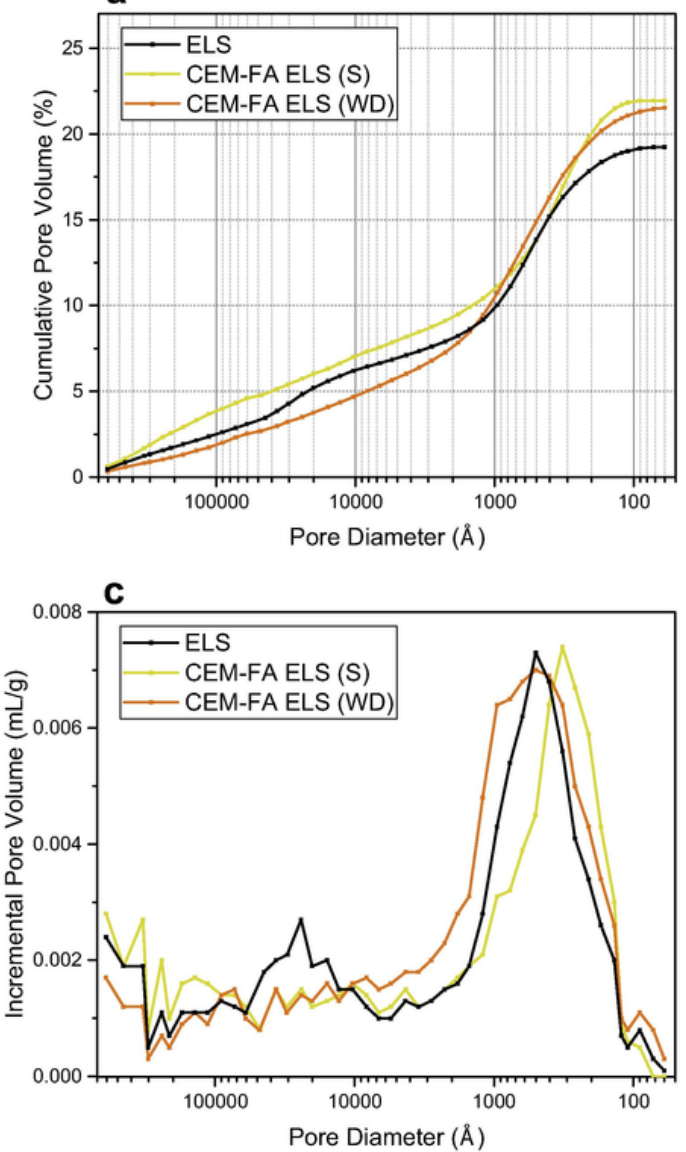

e

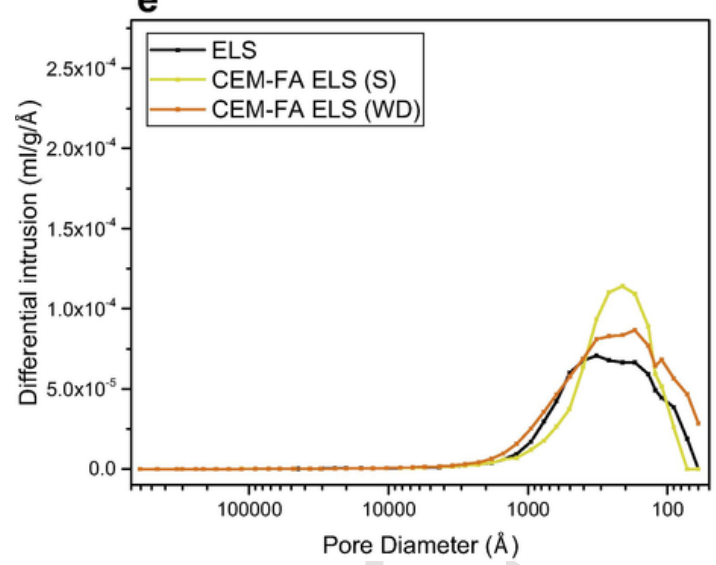

b

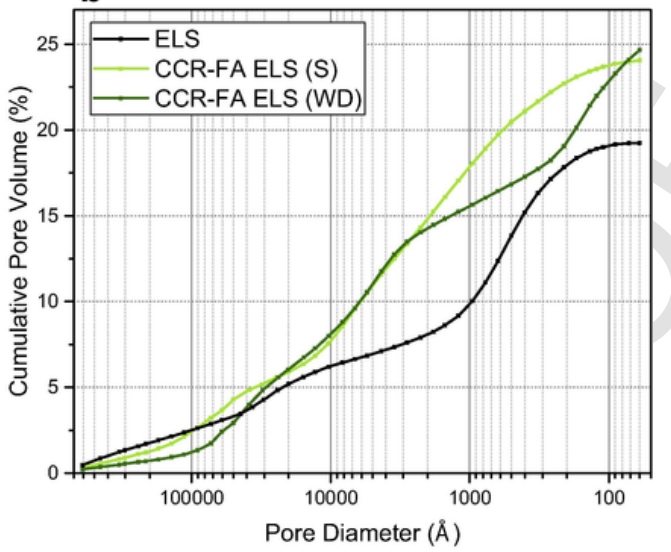

d

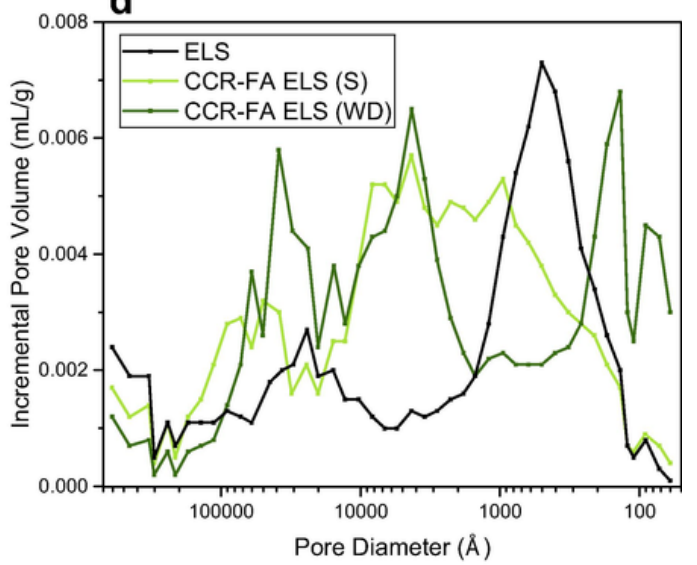

f

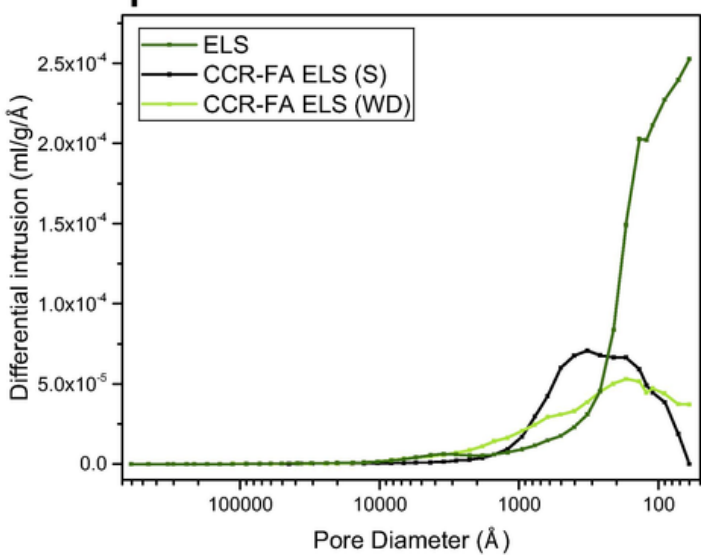

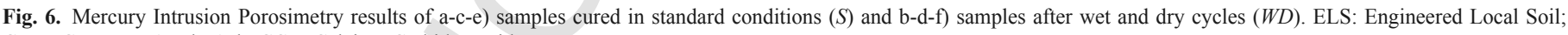
CEM: Cement; FA: Fly Ash; CCR: Calcium Carbide Residue.

under standard conditions. The difference was greatest for the mixture containing CCR and FA, which exhibited on average an increase of the compression strength of 2.4 times (reaching a peak of $9 \mathrm{MPa}$ ). The samples did not undergo any appreciable macroscopic swelling-shrinkage phenomenon during the wet and dry cycles [28], implying that any microstructural stress caused by the formation of new compounds and/or by the clay's swelling potential, if present, was limited. Mineralogical examinations demonstrated that the additional water available at each new cycle triggered the reaction of the unreacted FA and calcium hydroxide in the mixture, forming new hy- drated products. Although a different water content at testing may have influenced the UCS results, the formation of cementitious gel, which bound particles together, led undoubtedly to an increase of the mechanical strength.

Similar results to those found in the previous section were obtained by Nagaraj et al. [63] for cement-lime stabilised compressed earth blocks. In that work, the improvement in the mechanical properties was justified by the accelerated lime-soil reactions because of the high temperatures $\left(70{ }^{\circ} \mathrm{C}\right)$ used during the drying cycles of the test $[22,63]$. Hydration, in fact, is known to be a thermally activated 
a

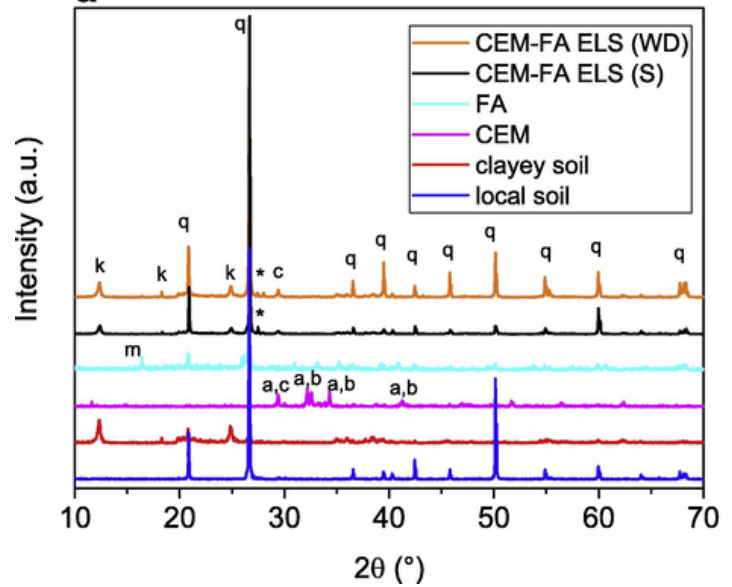

b

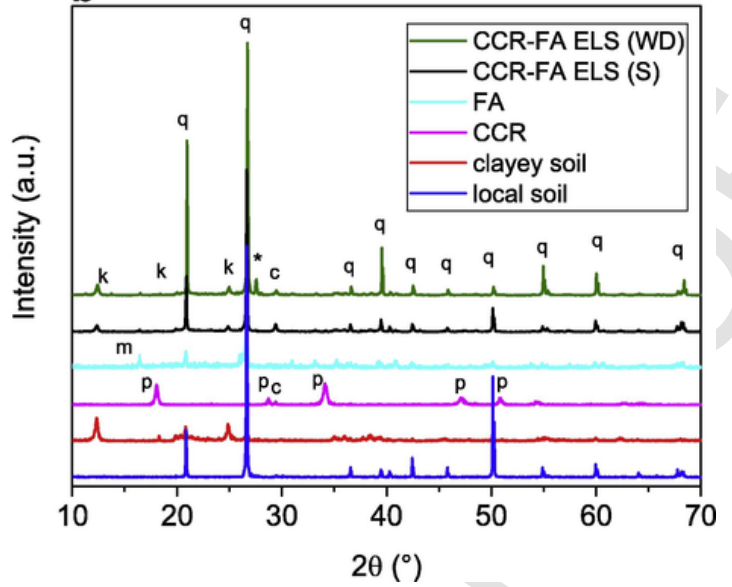

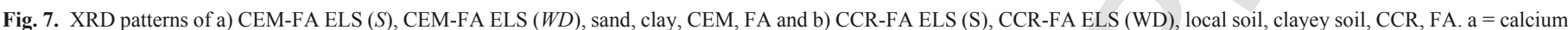

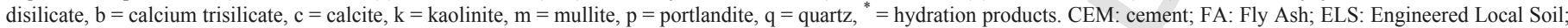
CCR: Calcium Carbide Residue.

a

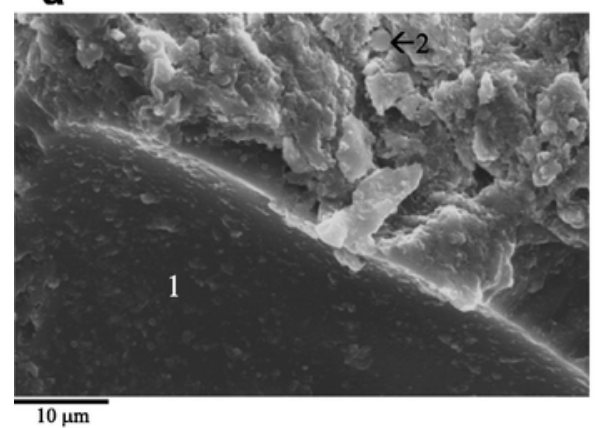

b

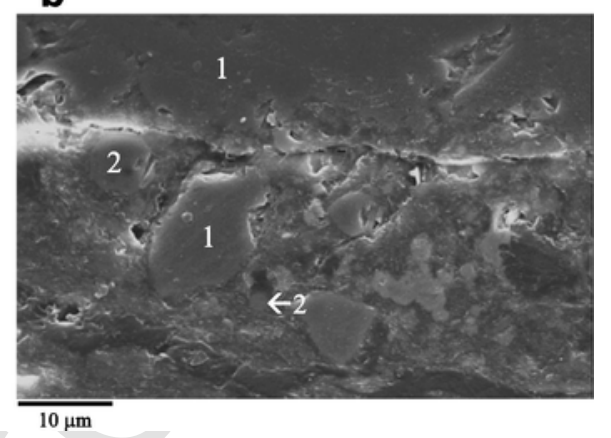

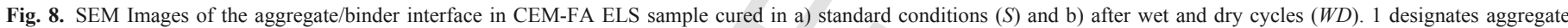
particles, 2 FA particles. CEM: Cement; FA: Fly Ash; ELS: Engineered Local Soil.
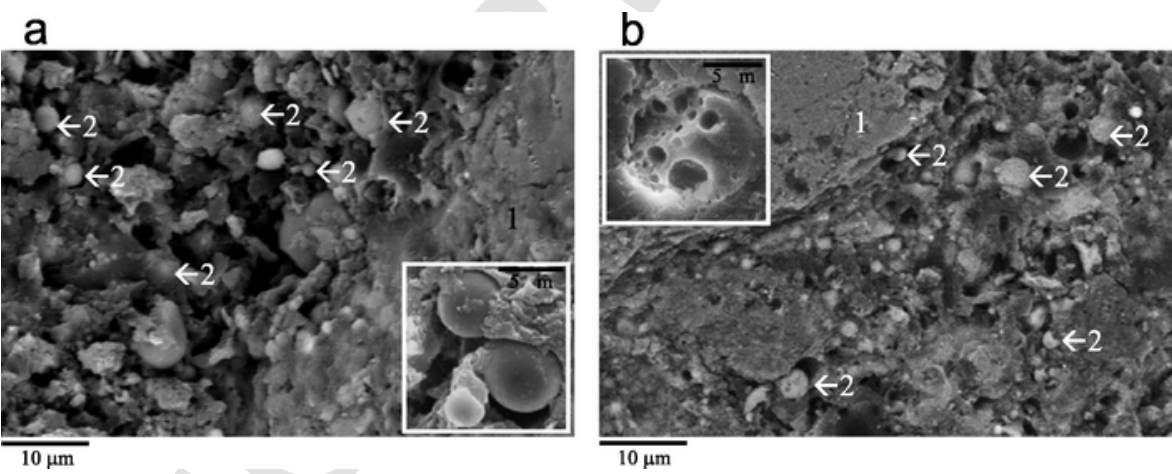

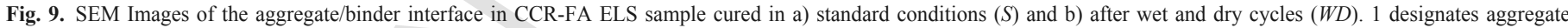
particles, 2 FA particles. CCR: Calcium Carbide Residue; FA: Fly Ash; ELS: Engineered Local Soil.

process which generates different products when temperature varies [64]. Toutanji et al. experienced the same behaviour for concrete containing FA and slag: a positive correlation between the increase in strength due to wet-dry exposure and the contents of FA and slag in the mixture, experiencing a maximum increase of over $30 \%$ for specimens with $30 \%$ FA [65].

CCR and FA stabilisation has been examined by a number of authors for compacted clayey soils. Contrary to findings discussed above, Bin-Shafique et al. experienced no significant effect on the UCS of compacted FA-stabilised fine-grained soils [66]. Opposite results to those found here have also been obtained: in [67-70], although stabilisation increased UCS, the strength of compacted clayey soils was adversely affected by wetting and drying cycles due to shrink-swell induced cracking and a gradual destruction of the pozzolanic reactions. As soils used here comprised relatively little clay, the adverse effects of shrink-swell cracking were avoided. 
Although the effects of drying temperature and water availability during the test were far from negligible in the increase of mechanical resistance, alternate wetting-drying would not be a realistic procedure to undertake under normal construction sites conditions to improve the mechanical properties of a RE wall. Moreover, such a treatment would considerably increase the environmental impacts of the wall, nullifying the benefits of using waste materials. Alternative ways to trigger the pozzolanic reactions applicable to real conditions with lower embodied environmental impacts are at the moment under investigation. For example, could the high summer temperatures and the natural rain of WA be enough to activate the reactions? If so, mechanical strength would probably increase with time without paying additional environmental costs.

\section{Conclusions}

This article investigated the impact of wetting-drying cycles on the mechanical and chemical properties of rammed earth mixes stabilised with waste materials. The following conclusions were drawn from the study:

1) Stabilisation drastically improved the mechanical properties of RE mixes cured at standard conditions. Stabilisation with CCR and FA cured at standard conditions did not achieve the same mechanical performance of CEM-FA stabilised RE.

2) Improved availability of water and the relatively high temperatures in the wetting and drying cycles triggered the pozzolanic reaction of the unreacted FA and calcium hydroxide in both CEM-FA and CCR-FA stabilised mixtures, leading to higher compressive strength.

3) Cyclic wetting-drying has been proved by several authors to have a detrimental effect on stabilised expansive soils, leading to destruction of the hydrated gel. In our case, the alternate cycles had a beneficial effect on the mechanical properties, probably due to the lower amount of clay and the presence of FA, which may have promoted autogenous healing.

4) The use of waste materials, such as FA and CCR, proved to be an effective solution to stabilise non-expansive soils typically used in RE construction.

\section{Acknowledgments}

The authors would like to thank the Australian Research Council (ARC) for providing the funding necessary to complete this work through the linkage project LP110100251. The authors wish also to acknowledge Paul Di Marco and Nathan Blackwell from the company Brikmakers, Justin Milton from Air Liquide and Bruce Hunter from Flyash Australia for their generous assistance throughout the experimental programme.

\section{References}

[1] P.A. Jaquin, C.E. Augarde, D. Gallipoli, D.G. Toll, The strength of unstabilised rammed earth materials, Géotechnique 59 (5) (2009) 487-490.

[2] D. Easton, The future and the common ground, Rammed Earth Construction, In Proceedings of the 1st International Conference on Rammed Earth Construction, ICREC, 2015, pp. 11-16.

[3] S. Dobson, Rammed earth in the modern world, Rammed Earth Construction, In: Proceedings of the 1st International Conference on Rammed Earth Construction, ICREC, 2015, pp. 3-10.

[4] M. Krayenhoff, Rammed earth in a concrete world, Rammed Earth Construction, In: Proceedings of the 1st International Conference on Rammed Earth Construction, ICREC, 2015, pp. 111-114.

[5] D.F. Pflughoeft-Hassett, B.A. Dockter, D.J. Hassett, K.E. Eylands, H.L. Lucinda, Use of Bottom Ash and Fly Ash in Rammed-Earth Construction, University of North Dakota, Grand Forks, ND, 2000.
[6] C.G. da Rocha, N.C. Consoli, A. Dalla, Rosa Johann, Greening stabilized rammed earth: devising more sustainable dosages based on strength controlling equations, J. Clean. Prod. 66 (2014) 19-26.

[7] N. Cristelo, S. Glendinning, T. Miranda, D. Oliveira, R. Silva, Soil stabilisation using alkaline activation of fly ash for self compacting rammed earth construction, Constr. Build. Mater. 36 (2012) 727-735.

[8] A.P.D.S. Milani, L.C. Labaki, Physical, mechanical and thermal performance of cement-stabilized rammed earth-rice husk ash walls, J. Mater. Civ. Eng. 24 (6) (2012) 775-782.

[9] R. Eires, Construção em Terra: Desempenho melhorado com incorporação de biopolímeros (Building with earth: improved performance with biopolymers incorporation), University of Minho, Guimarães, 2012.

[10] C. Kraus, D. Hirmas, J. Roberts, Compressive strength of blood stabilized earthen architecture, in: C. Mileto, F. Vegas, L. García, V. Cristini (Eds.), Earthen Architecture: Past, Present and Future, CRC Press, Boca Raton, Florida, 2015, pp. 217-220.

[11] Y. Millogo, J.-E. Aubert, A.D. Séré, A. Fabbri, J.-C. Morel, Earth blocks stabilized by cow-dung, Mater. Struct. 49 (11) (2016) 4583-4594.

[12] S. Jayakumar, J. Hemachander, J. Mohamedshahul Hameedh, Experimental study on properties of rammed earth blended with GGBS and silica flume, IJRET 5 (5) (2016) 295-297.

[13] A. Arrigoni, A.-C. Grillet, R. Pelosato, G. Dotelli, C.T.S. Beckett, M. Woloszyn, D. Ciancio, Reduction of rammed earth's hygroscopic performance under stabilisation: an experimental investigation, Build. Environ. (in press, DOI: 10.1016/j.buildenv.2017.01.034).

[14] Z.T. Yao, X.S. Ji, P.K. Sarker, J.H. Tang, L.Q. Ge, M.S. Xia, Y.Q. Xi, A comprehensive review on the applications of coal fly ash, Earth-Sci. Rev. 141 (2015) 105-121.

[15] J. Conti, P. Holtberg, J. Diefenderfer, A. LaRose, J.T. Turnure, L. Westfall, International Energy Outlook 2016 With Projections to 2040, U.S. Energy Information Administration (EIA), Washington, DC, 2016.

[16] C. Heidrich, H.-J. Feuerborn, A. Weir, Coal Combustion Products: A Global Perspective, World of Coal Ash (WOCA) Conference, Lexington, Kentucky, 2013.

[17] S. Kolias, V. Kasselouri-Rigopoulou, A. Karahalios, Stabilisation of clayey soils with high calcium fly ash and cement, Cem. Concr. Comp. 27 (2) (2005) 301-313.

[18] D.N. Little, E.H. Males, J.R. Prusinski, B. Stewart, Cementitious Stabilization, 79th Millenium Rep. Series, Transportation Research Board, Washington, D.C., 2000

[19] B.V. Venkatarama Reddy, P. Prasanna Kumar, Cement stabilised rammed earth Part A: compaction characteristics and physical properties of compacted cement stabilised soils, Mater. Struct. 44 (3) (2010) 681-693.

[20] F.G. Bell, Lime stabilization of clay minerals and soils, Eng. Geol. 42 (4) (1996) 223-237.

[21] M.R. Thompson, Factors influencing the plasticity and strength of lime-soil mixtures, Tech. Rep. Bull., 492, Engineering Experiment Station, University of Illinios, 1967.

[22] S.M. Rao, P. Shivananda, Role of curing temperature in progress of lime-soil reactions, Geotech. Geol. Eng. 23 (2005) 79-85.

[23] D. Ciancio, C.T.S. Beckett, J.A.H. Carraro, Optimum lime content identification for lime-stabilised rammed earth, Construct. Build. Mater. 53 (2014) 59-65.

[24] J.B. Croft, The Processes Involved in the Lime Stabilization of Clay Soils, Australian Road Research Board (ARRB) Conference, Melbourne, Australia, 19641169-1203

[25] F.A. Cardoso, H.C. Fernandes, R.G. Pileggi, M.A. Cincotto, V.M. John, Carbide lime and industrial hydrated lime characterization, Powder Technol. 195 (2) (2009) 143-149.

[26] S. Horpibulsuk, V. Munsrakest, A. Udomchai, A. Chinkulkijniwat, A. Arulrajah, Strength of sustainable non-bearing masonry units manufactured from calcium carbide residue and fly ash, Constr. Build. Mater. 71 (2014) 210-215.

[27] N.C. Consoli, P.D.M. Prietto, J.A.H. Carraro, K.S. Heineck, Behavior of compacted soil-fly ash-carbide lime mixtures, J. Geotech. Geoenviron. Eng. 127 (9) (2001) 774-782.

[28] A. Arrigoni, D. Ciancio, C.T.S. Beckett, G. Dotelli, Improving rammed warth walls's sustainability through Life Cycle Assessment (LCA), in: G. Habert, A. Schlueter (Eds.), Expanding Boundaries: Systems Thinking in the Built Environment. Sustainable Built Environment (SBE) Regional Conference, vdf Hochschulverlag AG an der ETH, Zürich, Zürich, 2016.

[29] J.-E. Aubert, A. Marcom, P. Oliva, P. Segui, Chequered earth construction in south-western France, J. Cult. Herit. 16 (3) (2015) 293-298.

[30] M.I. Gomes, T.D. Gonçalves, P. Faria, Unstabilized rammed earth: characterization of material collected from old constructions in south portugal and comparison to normative requirements, Int. J. Archit. Herit. 8 (2) (2013) 185-212.

[31] M. Hall, Y. Djerbib, Rammed earth sample production: context, recommendations and consistency, Constr. Build. Mater. 18 (4) (2004) 281-286.

[32] H. Houben, H. Guillaud, Earth Construction: A Comprehensive Guide, ITDG Publishing, Bradford, UK, 1994. 
[33] F. Champiré, A. Fabbri, J.-C. Morel, H. Wong, F. McGregor, Impact of relative humidity on the mechanical behavior of compacted earth as a building material, Constr. Build. Mater. 110 (2016) 70-78.

[34] Standards Australia, AS 1289.3.6.1-2009, Methods of Testing Soils for Engineering Purposes, Soil Classification Tests - Determination of the Particle Size Distribution of a Soil - Standard Method of Analysis by Sieving, Standards Australia, Sydney, 2009.

[35] Standards Australia, AS 1289.3.6.3-2003, Methods of Testing Soils for Engineering Purposes, Soil Classification Tests - Determination of the Particle Size Distribution of a Soil - Standard Method of Fine Analysis Using a Hydrometer, Standards Australia, Sydney, 2003

[36] Standards Australia, AS 1289.3.5.1-2006, Methods of Testing Soils for Engineering Purposes, Soil Classification Tests - Determination of the Soil Particle Density of a Soil - Standard Method, Standards Australia, Standards Australia, Sydney, 2006.

[37] Standards Australia, AS 1012.17-1997, Methods of Testing Concrete, Determination of the Static Chord Modulus of Elasticity and Poisson's Ratio of Concrete Specimens, Standards Australia, Sydney, 1997.

[38] ASTM, C618-15 Standard Specification for Coal Fly Ash and Raw or Calcined Natural Pozzolan for Use in Concrete, ASTM International, West Conshohocken, PA, 2015

[39] Standards Australia, AS 1289.5.2.1-2003, Soil Compaction and Density Tests, Determination of the Dry Density or Moisture Content Relation of a Soil Using Modified Compactive Effort, Standards Australia, Sydney, 2003.

[40] S. Burroughs, Recommendations for the Selection, Stabilization, and Compaction of Soil for Rammed Earth Wall Construction, J. Green Build. 5 (1) (2010) 101-114.

[41] Standards Australia, AS 1289.3.2.1-2009, Methods of Testing Soils for Engineering Purposes - Soil Classification Tests - Determination of the Plastic Limit of a Soil - Standard Method, Standards Australia, Sydney, 2009.

[42] C. Beckett, D. Ciancio, Effect of compaction water content on the strength of cement-stabilized rammed earth materials, Can. Geotech. J. 51 (5) (2014) 583-590.

[43] Q.-B. Bui, J.-C. Morel, First exploratory study on the ageing of rammed earth material, Materials 8 (1) (2014) 1-15.

[44] C.T.S. Beckett, D. Ciancio, Durability of cement-stabilised rammed earth: a case study in Western Australia, Aust. J. Civ. Eng. 14 (1) (2015) 54-62.

[45] ASTM, D559/D559M-15, Standard Test Methods for Wetting and Drying Compacted Soil-Cement Mixtures, ASTM International, West Conshohocken, PA, 2015.

[46] J.-C. Morel, Q.-B. Bui, E. Hamard, Weathering and durability of earthen materials and structures, in: M. Hall, R. Lindsay, M. Krayenhoff (Eds.), Modern Earth Buildings, Materials, Engineering, Construction and Applications, Woodhead Publishing Limited, Sawston, UK, 2012, pp. 282-303.

[47] R. Fitzmaurice, Manual on Stabilised Soil Construction for Housing, Technical Assistance Programme, United Nations, New York, 1958.

[48] D. Ciancio, J. Gibbings, Experimental investigation on the compressive strength of cored and molded cement-stabilized rammed earth samples, Constr. Build. Mater. 28 (1) (2012) 294-304.

[49] N.K. Sharma, S.K. Swain, U.C. Sahoo, Stabilization of a clayey soil with fly ash and lime: a micro level investigation, Geotech. Geol. Eng. 30 (5) (2012) 1197-1205.

[50] D.D. Tripura, K.D. Singh, Characteristic properties of cement-stabilized rammed earth blocks, J. Mater. Civ. Eng. 27 (7) (2015)

[51] S. Horpibulsuk, Strength and microstructure of cement stabilized clay, in: V. Kazmiruk (Ed.), Scanning Electron Microscopy, InTech, Rijeka, Croatia, 2012, pp. 439-460.
[52] J.-R. Zhang, X. Cao, Stabilization of expansive soil by lime and fly ash, J. Wuhan Univ. Technol. Mater. Sci. Ed. 17 (4) (2002) 73-77.

[53] S. Horpibulsuk, C. Phetchuay, A. Chinkulkijniwat, A. Cholaphatsorn, Strength development in silty clay stabilized with calcium carbide residue and fly ash, Soils Found. 53 (4) (2013) 477-486.

[54] S. Horpibulsuk, R. Rachan, A. Chinkulkijniwat, Y. Raksachon, A. Suddeepong, Analysis of strength development in cement-stabilized silty clay from microstructural considerations, Constr. Build. Mater. 24 (10) (2010) 2011-2021.

[55] Q.-B. Bui, J.-C. Morel, S. Hans, P. Walker, Effect of moisture content on the mechanical characteristics of rammed earth, Constr. Build. Mater. 54 (2014) 163-169.

[56] B.V. Venkatarama Reddy, P. Prasanna Kumar, Cement stabilised rammed earth Part B: compressive strength and stress-strain characteristics, Mater. Struct. 44 (3) (2010) 695-707.

[57] Y. Fan, S. Yin, Z. Wen, J. Zhong, Activation of fly ash and its effects on cement properties, Cem. Concr. Res. 29 (1) (1999) 467-472.

[58] M.P. Luxán, M.I. Sánchez de Rojas, M. Frías, Investigations on the fly ash-calcium hydroxide reactions, Cem. Concr. Res. 19 (1) (1989) 69-80.

[59] A.M. Neville, Properties of Concrete, Fourth ed., Longman Group Limited, Harlow, UK, 1995.

[60] K. Lemaire, D. Deneele, S. Bonnet, M. Legret, Effects of lime and cement treatment on the physicochemical, microstructural and mechanical characteristics of a plastic silt, Eng. Geol. 166 (2013) 255-261.

[61] P. Termkhajornkit, T. Nawa, Y. Yamashiro, T. Saito, Self-healing ability of fly ash-cement systems, Cem. Concr. Compos. 31 (3) (2009) 195-203.

[62] F. Massazza, Pozzolana and pozzolanic cements, in: P.C. Hewlett (Ed.), Lea's Chemistry of Cement and Concrete (Fourth ed.), Butterworth-Heinemann, Oxford, 1998, pp. 471-635.

[63] H.B. Nagaraj, A. Rajesh, M.V. Sravan, Influence of soil gradation, proportion and combination of admixtures on the properties and durability of CSEBs, Constr. Build. Mater. 110 (2016) 135-144.

[64] P. Blanc, X. Bourbon, A. Lassin, E.C. Gaucher, Chemical model for cement-based materials: temperature dependence of thermodynamic functions for nanocrystalline and crystalline C-S-H phases, Cem. Concr. Res. 40 (6) (2010) $851-866$.

[65] H. Toutanji, N. Delatte, S. Aggoun, R. Duval, A. Danson, Effect of supplementary cementitious materials on the compressive strength and durability of short-term cured concrete, Cem. Concr. Res. 34 (2) (2004) 311-319.

[66] S. Bin-Shafique, K. Rahman, M. Yaykiran, I. Azfar, The long-term performance of two fly ash stabilized fine-grained soil subbases, Resour. Conserv. Recy. 54 (10) (2010) 666-672.

[67] A. Kampala, S. Horpibulsuk, N. Prongmanee, A. Chinkulkijniwat, Influence of wet-dry cycles on compressive strength of calcium carbide residue-fly ash stabilized clay, J. Mater. Civ. Eng. 26 (4) (2014) 633-643.

[68] Y. Guney, D. Sari, M. Cetin, M. Tuncan, Impact of cyclic wetting-drying on swelling behavior of lime-stabilized soil, Build. Environ. 42 (2) (2007) 681-688.

[69] M. Temimi, J.P. Camps, M. Laquerbe, Valorization of fly ash in the cold stabilization of clay materials, Resour. Conserv. Recy. 15 (3-4) (1995) 219-234.

[70] A. Neramitkornburi, S. Horpibulsuk, S.L. Shen, A. Chinkulkijniwat, A. Arulrajah, M.M. Disfani, Durability against wetting-drying cycles of sustainable Lightweight Cellular Cemented construction material comprising clay and fly ash wastes, Constr. Build. Mater. 77 (2015) 41-49. 